RESEARCH ARTICLE

\title{
Removal and recovery of mercury from used fluorescent lamp glass by pyrolysis
}

\author{
R.G. Saman Wijesekara*, Ronald R. Navarro and Masatoshi Matsumura \\ Foundation for Advancement of International Science, 586-9 Akatsuka, Tsukuba City, Ibaraki, Japan.
}

Revised: 04 January 2011 ; Accepted: 20 May 2011

\begin{abstract}
Recovering mercury in metallic form from used fluorescent lamps is important for environmental safety and for its re-use in industry. Presently, pyrolysis has become a widely used thermal treatment technology for various wastes. Since it is performed under anaerobic conditions, the toxic metals are not oxidized and this minimizes their leaching from the treated material. This technology also reduces the risk of formation of toxic chloro-organic compounds such as dioxins. Therefore, in the study reported in this paper, pyrolysis was applied for the treatment of used fluorescent lamp glass, with special emphasis on mercury removal and recovery in metallic form. A laboratory scale pyrolyser was used for all the experiments. Pyrolysis was conducted at different temperatures using nitrogen as the carrier gas. A cold trap was attached to condense and recover metallic mercury from the flue gas. Results showed that a temperature of $600{ }^{\circ} \mathrm{C}$ is sufficient to achieve nearly $100 \%$ mercury removal. Around $20 \%$ of metallic mercury was recovered in the cold trap. The rest were trapped in the activated carbon filter and acid trap, showing that the process is able to completely prevent release of mercury to the environment.
\end{abstract}

Keywords: Fluorescent lamp, mercury recovery, mercury removal, pyrolysis, thermal treatment technology.

\section{INTRODUCTION}

Mercury is a hazardous material with known toxic health effects. Its presence in the environment is a persistent and growing problem due to its ability to bio-accumulate in various food chains (Jang et al., 2005). Mercury comes from a variety of sources including batteries, paints, dyes, electronic components and most significantly fluorescent lamp tubes. Based on a 1999 National Electrical Manufactures Association (NEMA) survey, an average four-foot fluorescent lamp contains about $11.6 \mathrm{mg}$ of mercury, but the amount varies with the size and the brand of the lamp. Though this concentration has considerably decreased over time, the use of fluorescent lamps in homes, schools, factories, office facilities, and parking lots has increased so that the problem still persists. Fluorescent lamps are usually preferred over incandescent lamps due to their efficient energy consumption (Hildenbrand et al., 2000). Nationwide, almost 600 million mercury containing lamps are discarded each year (ALMR, 2010), while the recycling rate is below $24 \%$. Despite the various actions of different countries to increase the recycling rate (Hilkene et al., 2005) most lamps are still incinerated or disposed with municipal solid wastes in landfill sites (ALMR, 2010). This could release higher amount of mercury to the environment (Changsuphan et al., 2003). Hence these lamps typically require special handling and treatment at the time of disposal.

Recovering metallic mercury from fluorescent lamps is important as it can be re-used in industry. The treated glass could also be recycled. Alternative treatment strategies include dry recycling, wet acid washing, aerobic thermal treatment and electrochemical treatment. The electrochemical process has been developed for gas phase mercury recovery (Paul \& David, 2002). Most lamp recyclers in the United States employ the dry process, where the lamps are crushed and the mercury vapour is captured by carbon filters. The mercury containing waste is transported to centers for further treatment and recovery of mercury (Jang et al., 2005). In Japan, wet acid washing is the preferred approach. This involves the crushing and washing of glass with strong hydrofluoric acid to remove mercury, and re-washing glass with pure water to remove excess acid. The acid solution passes through a special mercury absorbent and the treated acid is then recycled for lamp washing. The absorbent is finally cemented with special chelating agents and disposed at designated sites (personal communication, 4 August 2009). However, this process is complicated and has problems related to the leaching of mercury from cemented blocks.

\footnotetext{
*Corresponding author (samanwije@aol.com)
} 
There is a need to develop more practical and economical approaches to treat fluorescent lamps, with emphasis on mercury recycling and safety for handling the treated sample. In this connection, anaerobic thermal decomposition or pyrolysis is currently becoming a popular approach for use with various wastes. This process has been successfully applied for pilot-scale treatment of dioxin and polychlorinated biphenyl (PCB)contaminated sediments ( $\mathrm{Hu}$ et al., 2006). Due to the anaerobic conditions, the risk of further formation of such toxic chloro-organic compounds is minimized. In addition, toxic metals are also stabilized thus limiting their leachability (Hu et al., 2007). This research extends the application of pyrolysis for the treatment of used fluorescent lamp glass. It was postulated that this technology has special advantages for the removal and recovery of metallic mercury from fluorescent glass.

\section{METHODS AND MATERIALS}

Setting up and operation of the pyrolysis system: The pyrolysis system (ALS, Tsukuba, Japan) is shown in Figure 1 . The $8 \mathrm{~L}$ capacity quartz chamber is equipped with a sample holder and an internal temperature sensor. The condensation section cools down and collects the mercury vapour coming from the chamber. The temperature in the cold trap is around $0-5^{\circ} \mathrm{C}$ throughout the experiments. For safety purposes, a special type of activated carbon (DAISO, Japan) column was installed to adsorb mercury vapour that may escape from the condensation unit. A $2.5 \% \mathrm{HNO}_{3}$ acid trap was also added to remove any trace mercury prior to the release of exhaust gas to the surroundings.

During a typical operation, the required temperature programmes were initially saved in the machine. A measured amount of used fluorescent lamp glass, which was crushed to below one inch, was placed inside the chamber. The chamber cap was closed and sealed by tightening the screws. The glass manifold from the chamber to the condensation tank was heated and maintained at $220{ }^{\circ} \mathrm{C}$ throughout the experiment using a ribbon heater in order to avoid mercury condensation inside these tubes. The exhaust valve was closed and the vacuum pump was switched on to reduce the pressure to $-98.8 \mathrm{kPa}$ [assuming that no oxygen $\left(\mathrm{O}_{2}\right)$ or air remains inside]. At $-98.8 \mathrm{kPa}$, the inlet valve was automatically switched on to allow nitrogen $\left(\mathrm{N}_{2}\right)$ gas (purity $99.999 \%$ ) to purge the system at an initial flow rate of $1-2 \mathrm{~L} / \mathrm{min}$. The exhaust valve opens automatically when internal pressure reaches $3 \mathrm{kPa}$. At this point, the nitrogen flow was adjusted to the desired experimental condition. The heater was also turned on, allowing the temperature inside the chamber to increase and decrease according

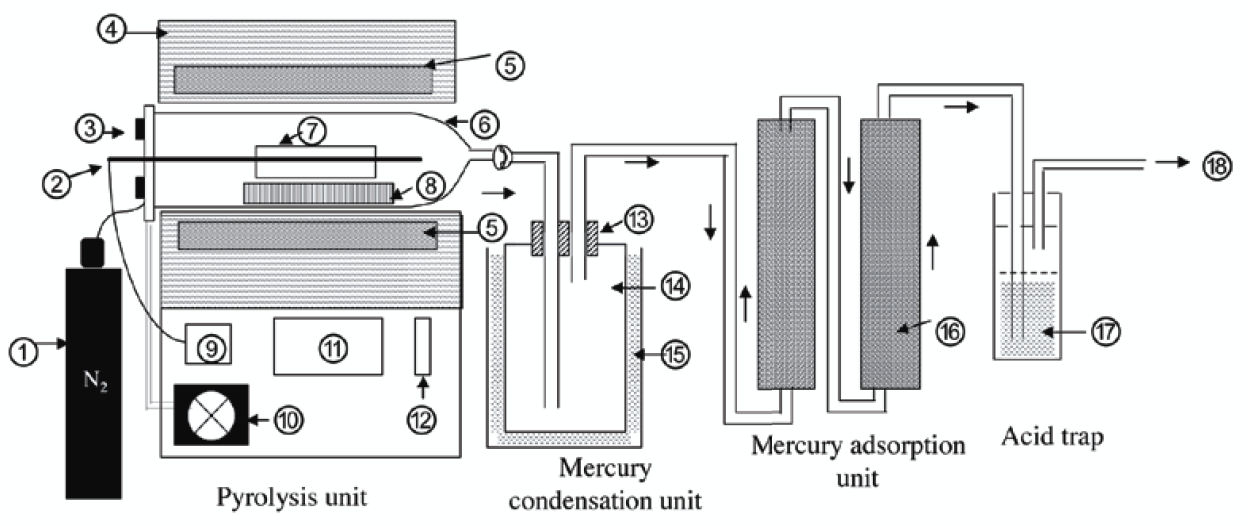

1. $\mathrm{N}_{2}$ gas cylinder
2. Temperature sensor
3. Pyrolysis chamber cap
4. Pyrolysis chamber cover
5. Heating device
6. Pyrolysis chamber (quartz tube)

7. Sample holder

8. Sample holder stand

9. Thermostat

10. Vacuum pump

11. Control panel

12. Gas flow meter
13. Silicon stopper
14. Mercury condensation bin
15. Cold trap with ice
16. Activated carbon
17. $\mathrm{HNO}_{3}$ acid
18. Exhaust gas

Figure 1: Pyrolysis system for the removal and recovery of mercury from fluorescent lamp glass 
to the programmed instructions. During the cooling stage, the cover of the chamber was opened when the temperature reached $400{ }^{\circ} \mathrm{C}$ to accelerate the cooling rate. When the temperature dropped to room temperature, the chamber cap was opened and the sample was collected. The treated sample was stored in a dark glass bottle prior to analysis. The tar, acid trap and activated carbon were also collected and stored in a refrigerator until analysis.

Mercury removal experiments: Using the above procedure, pyrolysis runs were conducted at different temperatures $\left(300,400,500,550,600,700\right.$ and $\left.800{ }^{\circ} \mathrm{C}\right)$ for $30 \mathrm{~min}$ to identify the best condition for mercury removal. Around 75-100 g of used lamps from Kinden Cooperation, Osaka, Japan were employed in each run. Nitrogen gas flow rate was $0.2 \mathrm{~L} / \mathrm{min}$.

Mercury recovery experiments: Since the mercury concentration of used fluorescent lamp glass was very small, experiments were first conducted using pure metallic mercury $\left(\mathrm{Hg}^{0}\right)$ in order to identify the suitable conditions for its recovery. Less than $0.3 \mathrm{~g}$ of mercury was used in each run. A series of experiments was conducted at different temperatures $\left(300-800{ }^{\circ} \mathrm{C}\right)$ at $0.2-2 \mathrm{~L} / \mathrm{min}_{2}$ gas flow rates. The adsorption capacity of activated carbon was also evaluated in these preliminary experiments. Final runs were conducted using approximately $2 \mathrm{~kg}$ of actual fluorescent lamps.

\section{Parameter analysis}

a) mercury analysis: All samples for mercury analysis were submitted to the Environmental Research Center, Tsukuba, Japan. The total mercury was analyzed according to Suzuki et al. (2004), for all liquid and solid samples.

b) metal analysis and leaching test: Crushed fluorescent lamp glass samples were subjected to hot acid digestion for complete dissolution of heavy metals following the standard methodologies described in American Public Health Association (APHA, 1995). The heavy metal contents (except mercury) of supernatants after digestion were analyzed by ICP 757 and 575 (Nippon Jarrel Ash Co., Ltd., Kyoto, Japan). Leaching tests were conducted following the standard methods of the Ministry of Environment, Japan (Suzuki et al., 2004).

\section{RESULTS AND DISCUSSION}

Mercury removal from used fluorescent lamp glass during pyrolysis

\section{Initial mercury content of fluorescent lamp glass}

The initial mercury contents of 3 representative used fluorescent lamps were found to range from $0.89-3.25 \mathrm{mg} / \mathrm{kg}$. For this analysis, fine particles below $2 \mathrm{~mm}$, which generally consists of phosphor powder, were pre-separated prior to the determination of the initial mercury content. A separate analysis of these particles revealed a very high content of mercury $(1100 \mathrm{mg} / \mathrm{kg})$, indicating that most of the mercury is concentrated in these fractions. Studies of Jang et al. (2005) have also reported very high concentrations of mercury in the phosphor powder, which is around $94.12-97.02 \%$ of total mercury present in the lamp (Jang et al., 2005). Since during the crushing process this powder readily detaches from the glass and settles down at the bottom of the crushing vessel, careful attention must be paid on their collection. As a consequence, the mercury content of lamps may vary significantly depending on the remaining phosphor powder attached to the glass. Furthermore, lamps manufactured 10-15 years ago have even higher content $(4700 \mathrm{mg} / \mathrm{kg})$ of mercury and these are also concentrated in the phosphor component (Bostick et al., 1996).

\section{Mercury removal efficiency during pyrolysis}

Compared to other metals, mercury generally exhibits a low boiling point of around $357{ }^{\circ} \mathrm{C}$. According to Edmonds et al.(1995), the vapour pressure of mercury increases drastically from 0 to $400{ }^{\circ} \mathrm{C}$. Table 1 shows the results of mercury removal during pyrolysis at different temperatures. As expected, a very high mercury removal of nearly $90 \%$ was observed even at $300{ }^{\circ} \mathrm{C}$ (Table 1 ). From $400{ }^{\circ} \mathrm{C}$, the removal further increased until close to $100 \%$ was achieved at $600{ }^{\circ} \mathrm{C}$ (Figure 2). However, glass deformation became apparent at $700{ }^{\circ} \mathrm{C}$ and the glass began to melt at $800{ }^{\circ} \mathrm{C}$. Therefore, the temperatures beyond $600{ }^{\circ} \mathrm{C}$ were considered unsuitable for actual applications.

The efficiency of mercury removal depends on the type and the brand of lamp. According to Jang et al. (2005), complete removal may be possible at $400{ }^{\circ} \mathrm{C}$ but in some cases, temperatures above $500{ }^{\circ} \mathrm{C}$ may still be insufficient. Through the system reported in the paper it was possible to achieve a maximum removal of $99.8 \%$ at $600{ }^{\circ} \mathrm{C}$ indicating that only $0.2 \%$ of mercury initially present in raw glass was detected in the treated sample. This small fraction of mercury may be considered as strongly bound to glass matrices. However, leaching test of the pyrolyzed lamp glass showed a positive result regarding the high stability of the residual mercury. The very low concentration of mercury in the supernatant 
Table 1: Mercury removal of fluorescent lamp glass during pyrolysis (30 min retention times) at different temperatures

\begin{tabular}{ccc}
\hline Experiment & $\begin{array}{c}\text { Pyrolysis } \\
\text { temperature }\left({ }^{\circ} \mathrm{C}\right)\end{array}$ & $\begin{array}{c}\text { Mercury removal } \\
(\%)\end{array}$ \\
\hline & 300 & 89.5 \\
2 & 400 & 89.7 \\
3 & 500 & 94.8 \\
4 & 600 & 99.8 \\
5 & 700 & 99.8 \\
6 & 800 & 99.6 \\
\hline
\end{tabular}

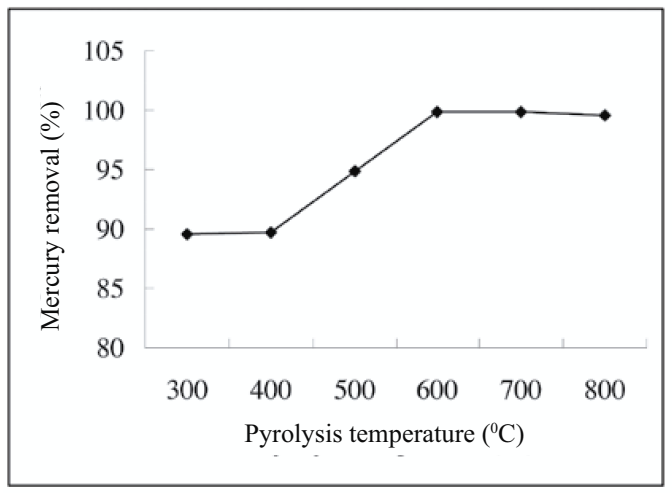

Figure 2: Mercury removal efficiency at different pyrolysis temperatures

$(<0.0005 \mathrm{mg} / \mathrm{L})$ indicates that the treated glass can be disposed safely if not recycled.

\section{Mercury recovery}

\section{Mercury recovery with pure metallic mercury}

Since the mercury concentration of used fluorescent lamp glass was low, pure metallic mercury was used for the initial studies to establish suitable conditions for its recovery. It was found that the best temperature for maximum mercury removal, without changing the glass quality, was $600{ }^{\circ} \mathrm{C}$. Recovery tests were therefore conducted at $550-600{ }^{\circ} \mathrm{C}$ at a holding time of $60 \mathrm{~min}$.

Preliminary runs showed that mercury condensation occurred inside the glass tubes between the chamber and cold trap since the temperature in this section was below $100{ }^{\circ} \mathrm{C}$. To prevent such condensation, these tubes were separately heated up to $220{ }^{\circ} \mathrm{C}$. After this adjustment, metallic mercury condensation was successfully channeled to the desired collection tank. Table 2 shows that almost all metallic mercury (100\%) can be recovered during pyrolysis.

Generally, the mercury containing wastes are placed in a retort and heated for long hours (4-24 hours) at a temperature of above $357{ }^{\circ} \mathrm{C}$ (boiling point of mercury) and below $550{ }^{\circ} \mathrm{C}$ (Truesdale et al., 1993). In the system reported in this paper, the total time for the removal and recovery of mercury, including the heating and cooling stages, was only around 6 hours, suggesting that it is comparable if not superior in performance relative to established methods.

For comparison, a similar experiment was also conducted in the presence of air, instead of nitrogen to simulate incineration conditions. The air flow rate was maintained at $1 \mathrm{~L} / \mathrm{min}$. Results showed that only around $10 \%$ of metallic mercury could be recovered under this condition. The rest may possibly be in the form of $\mathrm{HgO}$ and dihalide species such as $\mathrm{HgCl}_{2}, \mathrm{HgF}_{2}, \mathrm{HgI}_{2}$ and $\mathrm{HgBr}_{2}$ (Figure 3). Zhao et al. (2010) recently reported that mercury oxidation is considerably higher in the presence of oxygen than with nitrogen. In addition, mercury oxidation with air in the presence of chlorine can also produce $\mathrm{HgCl}_{2}$ (Puchakayala et al., 2006). $\mathrm{HgCl}_{2}$ formation decreases at temperatures above $600{ }^{\circ} \mathrm{C}$. These reactions could probably explain the low recovery of mercury in its metallic form during the simulated incineration runs.

\section{Mercury recovery from used fluorescent lamp glass}

Initial tests for mercury recovery from actual fluorescent lamps were conducted using small samples (75-100 g). With this amount, a recovery of $10-25 \%$ in the cold trap was achieved. However, the formation of metallic mercury in the condensation tank was not observed. In order to scale up the recovery, a larger quantity of crushed sample $(2 \mathrm{~kg})$ was used. Under this condition, clear formation of metallic mercury was observed in the cold trap (Figure 4). Nevertheless, mass balance calculation still revealed an incomplete recovery. Analysis has revealed that $31.9 \mathrm{mg}$ of metallic mercury was present in the condensation tank, which corresponds to around 19\% of the total mercury in the $2 \mathrm{~kg}$ fluorescent lamp. In this regard, it is extremely important that mercury, regardless of form, should be prevented from being released to the environment. This study has confirmed that activated carbon is well-suited for this purpose. Huang et al. (2008) reported that commercially available activated carbon absorbs $50.5 \%$ of elemental or metallic mercury. They have also mentioned that the activated carbon produced from chicken waste absorbs $68.8 \%$ of elemental $\mathrm{Hg}$ in the flue gas (Huang et al., 2008). In this study, the special 
type of activated carbon utilized (DAISO, Japan) was confirmed to absorb a very large amount of around $13 \mathrm{mg}$ mercury/g of carbon (Figure 6). Through this application, a huge fraction $(77 \%)$ of the total mercury that escaped the cold trap was trapped. Finally, the remaining 3.3\%

Table 2: Mercury recovery during pyrolysis. A pure metallic mercury was employed in these runs.

\begin{tabular}{ccc}
\hline Experiment & $\begin{array}{c}\text { Amount of } \mathrm{Hg} \\
\text { used }(\mathrm{g})\end{array}$ & Percentage recovery \\
\hline 1 & 0.1110 & 99 \\
2 & 0.1305 & 100 \\
3 & 0.2553 & 101 \\
4 & 0.3484 & 105 \\
\hline
\end{tabular}

(a)

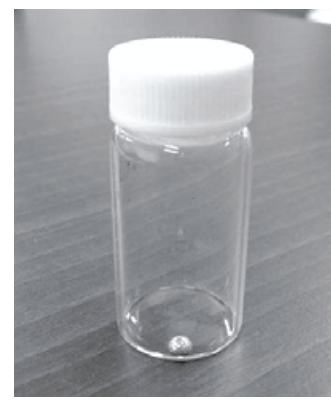

(b)

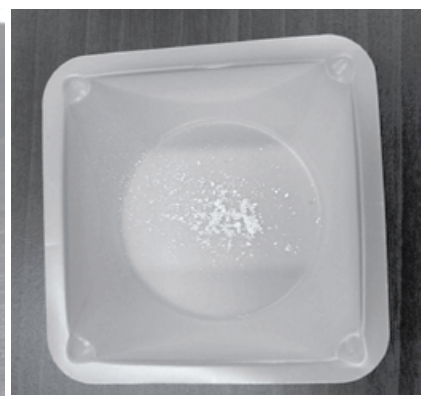

Figure 3: Recovered mercury during (a) pyrolysis at $550^{\circ} \mathrm{C}$ at $1 \mathrm{~L} / \mathrm{min}$ $\mathrm{N}_{2}$ gas flow in the form of metallic and (b) incineration at $550{ }^{\circ} \mathrm{C}$ at $1 \mathrm{~L} / \mathrm{min}$ air flow was detected in the acid trap. The distribution of mercury after treatment is summarized in Figure 5 and Table 3. These data show the superior safety feature of the system in preventing the release of highly toxic mercury to the environment during treatment.

Table 3: Mass balance of mercury during thermal treatment of fluorescent lamp glass. The $\mathrm{Hg}$ content is in $\mathrm{mg}$.

\begin{tabular}{lrrr}
\hline & Replicate 1 & Replicate 2 & Mean \\
\hline Initial & 166.6 & 168.3 & 167.5 \\
Cold trap & 31.5 & 32.2 & 31.9 \\
Activated carbon column & 127.5 & 132.4 & 130 \\
Acid trap & 5.7 & 5.6 & 5.6 \\
\hline
\end{tabular}

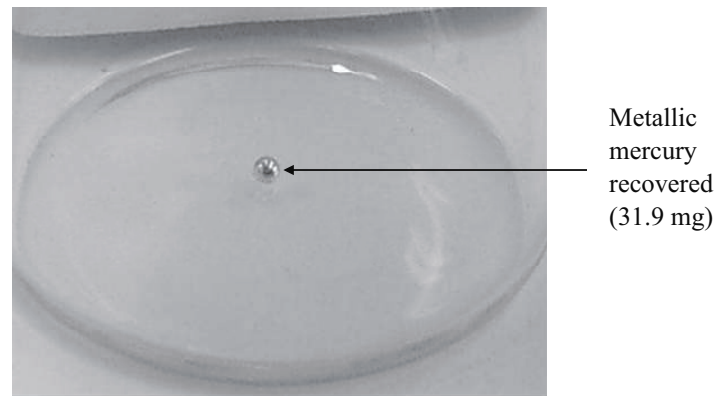

Figure 4: Mercury recovered in the metallic form during pyrolysis of fluorescent lamp glass at $550{ }^{\circ} \mathrm{C}$ at $1 \mathrm{~L} / \mathrm{min} \mathrm{N}_{2}$ gas flow rate for 60 min pyrolysis time

$\begin{array}{lll}\begin{array}{l}\text { Pyrolysis } \\ \text { chamber }\end{array} & \text { Cold trap unit } & \begin{array}{l}\text { Activated } \\ \text { carbon } \\ \text { column }\end{array}\end{array}$

Amount of $\mathrm{Hg}$ in $\mathrm{mg}$
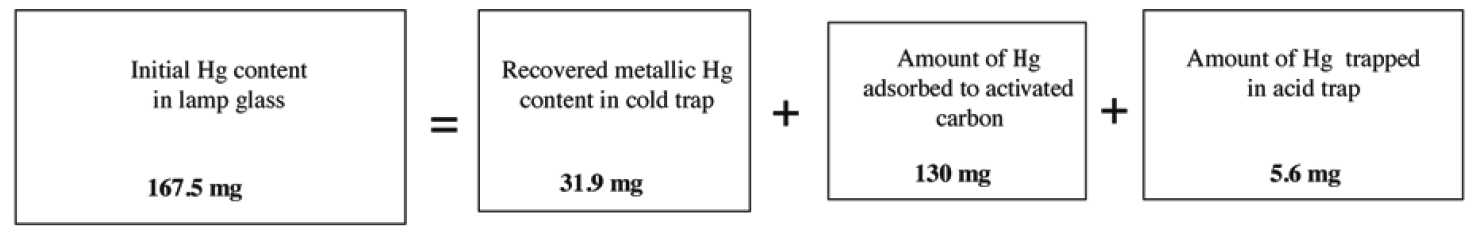

Amount of $\mathrm{Hg}$ in percentage
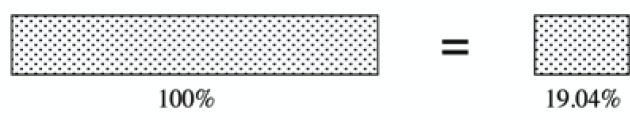
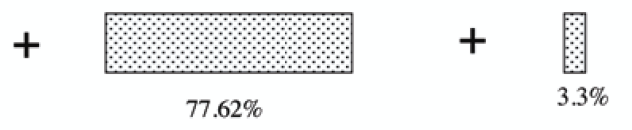

Figure 5: Mass balance of mercury during mercury recovery from used fluorescent lamp glass by pyrolysis 


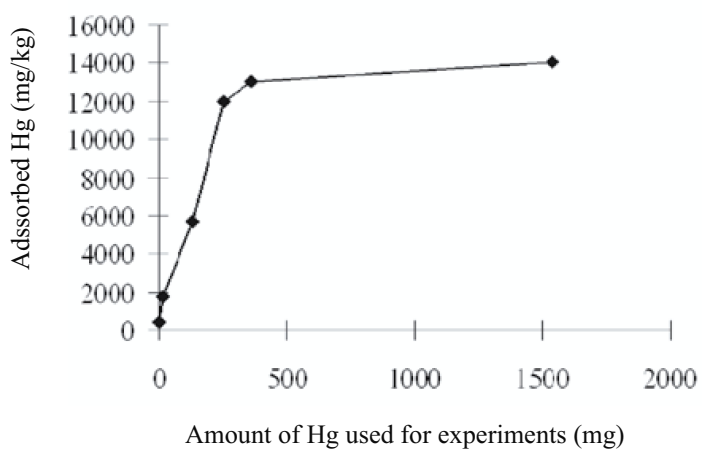

Figure 6: Mercury adsorption capacity of the activated carbon used during treatment

(a)

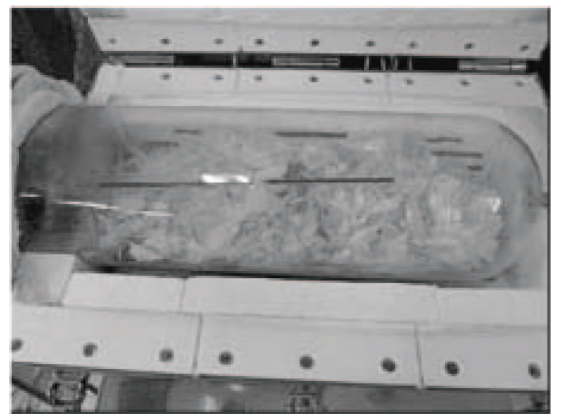

(b)

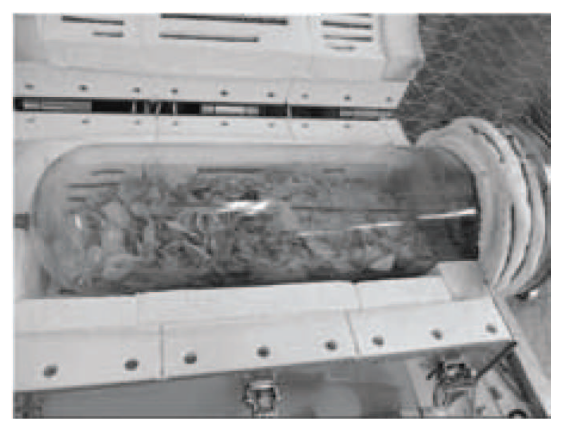

Figure 7: Appearance of fluorescent lamp glass a) before and b) after pyrolysis at $550{ }^{\circ} \mathrm{C}$ for $60 \mathrm{~min}$

From estimates of the above data, $8000 \mathrm{mg}$ of metallic mercury may be recovered per ton of used lamp glass. However, it must be emphasized that this may vary depending on the size of lamps as well as the amount of mercury present at the time of treatment etc. (Raposo et al., 2003). There is an immediate concern about the handling of the activated carbon, where the majority of the volatilized mercury is trapped. Although a second stage pyrolysis is a reasonable choice, more investigations are necessary to evaluate the conditions that would enhance their recovery in the cold trap as metallic mercury, considering that most fractions were concentrated in the activated carbon. Detailed work on this aspect will be considered in the future.

In addition to mercury, the fluorescent lamp glass may also contain other organic and inorganic compounds. ICP analyses also showed that both raw and pyrolyzed glass contain $\mathrm{P}, \mathrm{Si}, \mathrm{Na}, \mathrm{Al}, \mathrm{Mg}$ and $\mathrm{K}$. However, their individual concentrations were less than $2 \mathrm{ppm}$. Chang et al. (2007) have reported that the phosphor powder has traces of rare earth metals such as $\mathrm{La}, \mathrm{Gd}, \mathrm{Tb}$ and $\mathrm{En}$. In the same study, $\mathrm{SiO}_{2}, \mathrm{Na}_{2} \mathrm{O}, \mathrm{MgO} \mathrm{K}_{2} \mathrm{O}, \mathrm{PbO}$, and some organic compounds have also been detected (Chang et al., 2007). During pyrolysis the apparent decomposition of organic compounds was observed (Figure 7). The pyrolyzed sample acquired a black colouration. However, with such limited qualitative data, not much can be said about the fate of these compounds. This is yet another interesting topic for future investigations on the pyrolysis of fluorescent lamps.

\section{REFERENCES}

1. Association of Lighting and Mercury Recyclers (ALMR) (2010). Recycling of Mercury Containing Lighting. Association of Lighting and Mercury Recyclers, Napa, California, USA. Available at http://www.almr.org/ suppor files/messageforall.htm, Accessed 10 December 2010.

2. American Public Health Association (APHA) (1995). Standard Methods for the Examination of Water and Wastewater, $19^{\text {th }}$ edition, p. 1325. American Public Health Association, Washington DC, USA.

3. Bostick W.D., Beck D.E., Bowser K.T., Bunch D.H., Fellows R.L. \& Sellers G.F. (1996). Treatability study for removal of leachable mercury in crushed fluorescent lamps. Lockheed Martin Energy Systems, Inc., for the U.S. Department of Energy, pp. 1-39. Available at http://www. osti.gov/bridge/purl.cover.jsp? purl=/193903-TV0vF7/ webviewable/, Accessed 7 December 2010.

4. Chang T.C., Wang S.F., You S.J. \& Cheng A. (2007). Characterization of halophosphate phosphor powders recovered from the spent fluorescent lamps. Journal of Environmental Engineering and Management 17(6): 435-439.

5. Changsuphan A., Kerdsuwan S. \& Bashkim V.N. (2003). Efficiency of mercury removal in packed-bed wet scrubber from infectious waste incinerator. The Journal of KMITNB 13(4): 1-8.

6. Edmonds B., Moorwood R.A.S. \& Szczepanski R. (1996). Mercury Partitioning in Natural Gases and Condensates. Gas Processors Association (GPA) European Chapter Meeting, London, UK, 21 March, pp. 1-4. Available at http://www.infochemuk.com/publicat/papers/hgtalk.pdf, Accessed 05 December 2010.

7. Hildenbrand V.D., Denissen C.J.M., Geerdinck L.M., Van der Marel C., Snijders J.H.M. \& Tamminga Y. (2000). Interactions of thin oxide films with a low-pressure 
mercury discharge. Thin solid Films 371 (1-2): 295-302.

8. Hilkene C. \& Friesen K. (2005). Background study on increasing recycling of end-of-life mercury-containing lamps from residential and commercial sources in Canada. Action Plan 2000 on Climate Change, Enhanced Recycling Program, Environment Canada Natural Resources Canada, pp. 1-97. Available at http://www.pollutionprobe. org/Reports/merclampsreport.pdf, Accessed 9 December 2010.

9. $\mathrm{Hu}$ Z., Wijesekara S.R.G., Navarro R.R., Wu D., Zhang D., Matsumura M. \& Kong H. (2006). Removal of PCDD/ Fs and PCBs from sediment by oxygen free pyrolysis. Journal of Environmental Sciences 18(5): 989-994.

10. Hu Z., Navarro R., Nomura N., Kong H., Wijesekara S. \& Matsumura M. (2007). Changes in chlorinated organic pollutants and heavy metal content of sediments during pyrolysis. Environmental Science Pollution Research International 14(1):12-8.

11. Huang Y., Jin B., Shong Z., Zhong W. \& Xiao R. (2008). Characteristics and mercury adsorption of activated carbon produced by $\mathrm{CO}_{2}$ of chicken waste. Journal of Environmental Sciences 20 (3): 291-296.

12. Jang M., Hong S.M. \& Park J. K. (2005). Characterization and recovery of mercury from spent fluorescent lamps. Waste Management 25(1): 5-14.

13. Paul T.B. \& David C.S. (2002). An electrochemical system for removing and recovering elemental mercury from a gas stream. Environmental Science and Technology 36(20): 4430-4435.

14. Puchakayala M.B. (2006). Mercury emission behavior during isolated coal particle combustion. Ph D thesis, Texas A \& M University, Texas, USA.

15. Raposo C., Windmoller C.C. \& Junior W.A.D. (2003). Mercury speciation in fluorescent lamps by thermal release analysis. Waste Management 23: 379-886.

16. Suzuki T., Akagi H., Arimura K., Ando T., Sakamoto M., Satoh H., Naganumba A., Futatsuka M. \& Matsuyama S. (2004). Mercury Analysis Manual. Ministry of Environment, Tokyo, Japan. Available at http://www.nimd. go.jp/kenkyu/docs/march_mercury_analysis_manual(e). $p d f$, Accessed 4 December 2010.

17. Truesdale R.S., Beaulieu S.M. \& Pierson T.K. (1993). Management of used Fluorescent Lamps: Preliminary Risk Assessment. Research Triangle Institute for the Office of Solid Waste, U.S. Environmental Protection Agency, Research Triangle Park, North Carolina, USA. Available at http://www.apliquim.com.br/downloads/nema.pdf, Accessed 7 December 2010.

18. Zhao Y. C., Zhang J.Y., Liu J., Diaz-Iaz-Somoano M., Martinez-Tarazona M.R. \& Zheng C.G. (2010). Study on mechanism of mercury oxidation by fly ash from coal combustion. Chinese Science Bulletin 55(2): 163-167. 